\title{
A narrative overview of active surveillance for clinically localised prostate cancer.
}

BATES, A.S., KOSTAKOPOULOS, N., AYERS, J., JAMESON, M., TODD, J., LUKHA, R., CYMES, W., CHASAPI, D., BROWN, N., BHATTACHARYA, Y., PATERSON, C. and LAM, T.B.L. 


\section{A narrative overview of active surveillance for clinically localised prostate cancer}

Bates AS (BSc (Hons), MBChB, MSc (Oxon), MRCS), ${ }^{1}$ Kostakopoulos N (MD, PhD), ${ }^{1}$ Ayers J (BMBCh MRCS), ${ }^{1}$ Jameson M (MBChB), ${ }^{2}$ Todd J (BSc, MSc, MBChB), ${ }^{3}$ Lukha R (MBChB, MSc (Oxon), MFPH), ${ }^{4}$, Cymes W (BA (Hons), MBBChir, MRCS), ${ }^{1}$ Chasapi D (BSc (Hons)), ${ }^{5}$ Brown N (BSc (Hons), MBChB), ${ }^{5}$ Bhattacharya Y (BSc (Hons), MBChB), ${ }^{5}$ Paterson C (BA, MSc, PgCert LTA, FHEA, PG Nonmedical prescriber, RAN), ${ }^{6}$ Lam TBL (MBChB, FRCSEd (Urology), PhD) ${ }^{1,7 *}$

1. Department of Urology, Aberdeen Royal Infirmary, Foresterhill, Aberdeen AB25 2ZN, Scotland

2. Warrington and Halton Teaching Hospitals NHS Foundation Trust.

3. Worcester Acute Hospitals NHS Trust

4. Oxford University Hospitals NHS Foundation Trust

5. University of Aberdeen School of Medicine, Foresterhill, Aberdeen AB25 2ZD, Scotland

6. University of Canberra, School of Nursing, Midwifery and Public Health, Canberra ACT 2601, Australia

7. Academic Urology Unit, University of Aberdeen, Foresterhill, Aberdeen AB25 2ZD, Scotland

${ }^{*}$ Contact author: Mr. Thomas B. L. Lam, Consultant Urological Surgeon and Honorary Senior Clinical Lecturer, Department of Urology, Aberdeen Royal Infirmary, Foresterhill, Aberdeen AB25 2ZN, Scotland. Tel: +44-1224-553417. E-mail: thomasbllam@abdn.ac.uk

\section{Abstract}

Background Active surveillance (AS) is a strategy employed as an alternative to immediate standard active treatments for patients with low or intermediate-risk localised prostate cancer (PCa). Active treatments such as radical prostatectomy and radiotherapy are associated with significant adverse effects which impair quality of life. There is robust data indicating that the majority of patients with lowrisk PCa undergo a slow and predictable course of cancer growth, and hence do not require immediate active curative treatment. AS provides a means to identify patients with low-risk PCa to be monitored closely through regular clinical assessments, PSA testing, imaging using MRI scans and regular repeat prostate biopsies. These measures enable the identification of any change in disease characteristics which indicate progression or increase in cancer extent or aggressiveness, which necessitates active curative treatment. Alternatively, some patients may choose to leave AS to pursue curative interventions due to anxiety or development of adverse effects such as infections from regular repeat biopsies. The main benefit of AS is the avoidance of unnecessary radical treatments for patients at the early stages of the disease, hence avoiding over-treatment, whilst identifying those at risk of progression to be 
treated actively. The objective of this article is to provide a narrative summary of contemporary practice regarding AS based on a review of the available evidence base and clinical practice guidelines. Elements of discussion include the potential clinical effectiveness and harms of AS, what AS involves from a practical perspective for healthcare professionals, and patient perspectives. The pitfalls and challenges for healthcare professionals undertaking AS due to variable definitions and thresholds are also considered. Data sources We consulted international guidelines, national and international collaborative studies and seminal prospective studies on AS in the management of clinically localised PCa. Therefore this article constitutes a narrative review and critique of the current evidence base regarding AS. Conclusions AS is a feasible alternative to radical treatment options, especially for lowrisk PCa, primarily as a means of avoiding over-treatment for patients with early disease, whilst identifying those who are at risk of disease progression for active treatment. There is emerging data demonstrating the long-term safety of AS as an oncological management strategy. Uncertainties remain regarding variation in definitions, criteria, thresholds and the most effective types of diagnostic interventions pertaining to patient selection, monitoring and reclassification. Efforts have been made to standardise the practice and conduct of AS, and these are continuing. As data from high-quality prospective comparative studies mature, the practice of AS will continue to evolve and outcomes are expected to continue to improve. Implications for nursing practice The practice of AS involves a multi-disciplinary team of healthcare professionals consisting of nurses, urologists, oncologists, pathologists and radiologists. Nurses play a prominent role in delivering and managing AS programmes, and are closely involved in all stages including patient selection and recruitment, counselling, organising and administering diagnostic interventions including prostate biopsies, and ensuring patients' needs are being met throughout the duration of AS. The article briefly summarises the role of nurses in AS programmes. 


\section{Introduction}

This article introduces the reader to active surveillance (AS) for clinically localised prostate cancer (PCa). Prostate cancer is now the commonest non-cutaneous malignancy. ${ }^{1}$ Over 10,000 men in the UK die from PCa per year and the disease represents an oncological public health priority. ${ }^{2}$ The diagnosis of prostate cancer is based on clinical examination and estimation of serum prostate specific antigen (PSA) followed by transrectal ultrasound (USS)-guided prostate biopsies. Recently, the use of prostate MRI scan prior to biopsies have been propose. ${ }^{3}$ The majority of patients present with localised (or organ-confined) PCa, and this article focuses exclusively on such patients. Patients with localised PCa can be stratified further into three different categories based on the risk of progression and subsequent death, using clinical variables including clinical T stage (i.e. local extent of cancer), PSA blood test and grade of cancer (i.e. Gleason sum score or ISUP grade group) based on biopsies; these include low, intermediate and high-risk groups (see Table 1). ${ }^{4} 53$ Treatment with curative intent for localised PCa is dependent on patient factors including co-morbidities and life expectancy, and the nature of the disease including the risk grouping and extent of cancer within the prostate gland. Curative treatments (i.e. radical treatment) either entails surgery to remove the prostate (i.e. radical prostatectomy) or radiotherapy (i.e. external beam radiotherapy or interstitial brachytherapy). These treatments are usually offered to patients with organ-confined disease and who have a greater than a 10-year life expectancy. ${ }^{3}$ For men with less than a 10-year life expectancy, a deferred non-curative interventional policy is employed (i.e. watchful waiting), whereby patients are monitored for signs of progression to locally advanced or metastatic stage at which point hormonal therapy is commenced. Treating PCa with curative intent incurs potentially significant side effects. Radical prostatectomy is associated with the risks of any major pelvic operation, and specifically, erectile dysfunction and urinary stress incontinence. Radiotherapy risks radiation toxicity to the pelvic organs, especially the bowel and bladder. The effects of radiotherapy may include intractable bladder pain, haemorrhagic cystitis, proctitis, rectal bleeding and erectile dysfunction. There is also a small risk of developing secondary cancer of the bowel and bladder from radiation injury further down the line ${ }^{6,7}$

Active surveillance (AS), or deferred active treatment, is a strategy employed as an alternative to immediate standard active treatments for low or intermediate-risk localised PCa. This is based on the premise that such patients do not require immediate treatment due to the favourable natural history 
of untreated early PCa, with the majority of patients undergoing a slow and predictable pattern of cancer growth. This phenomenon, coupled with the unfavourable side effect profile of radical treatments, means that a policy of surveillance, whereby patients are monitored closely for signs of disease progression, increase in cancer grade or disease extent, can be safely employed in order to avoid unnecessary treatments until a point when it becomes clinically necessary, or until the patient changes his mind and wants to pursue active treatment instead. AS has emerged as a feasible alternative to radical treatments, and is an increasingly important means of avoiding over-treatment of low-risk PCa.

The objective of this article is to provide a narrative summary of contemporary practice regarding AS based on a review of the available evidence base and clinical practice guidelines. Elements of discussion include the evidence of clinical effectiveness for AS, what AS involves from a practical perspective for healthcare professionals, patient perspectives, and pitfalls and challenges for healthcare professionals in undertaking AS due to clinical heterogeneity including variable definitions and thresholds, and finally implications for nursing practice.

Table 1: EAU risk stratification for prostate cancer biochemical recurrence following treatment $^{3}$

\begin{tabular}{|l|l|l|l|}
\hline \multicolumn{1}{|c|}{ Low risk } & \multicolumn{1}{|c|}{ Intermediate risk } & \multicolumn{1}{|c|}{ High Risk } & \multicolumn{1}{c|}{ Locally advanced } \\
\hline $\begin{array}{l}\text { PSA }<10 \mathrm{ng} / \mathrm{mL} \\
\text { and GS }<7 \text { (ISUP } \\
\text { Grade 1) } \\
\text { and cT1-2a }\end{array}$ & $\begin{array}{l}\text { PSA 10-20 } \mathrm{ng} / \mathrm{mL} \\
\text { or GS 7 (ISUP Grade } \\
2 / 3)\end{array}$ & $\begin{array}{l}\text { PSA }>20 \mathrm{ng} / \mathrm{mL} \\
\text { or GS }>7 \text { (ISUP Grade } \\
\text { or cT2b }\end{array}$ & $\begin{array}{l}\text { ar cT2c } \\
\text { any PSA } \\
\text { any GS (any ISUP } \\
\text { Grade) } \\
\text { cT3-4 or cN }+\end{array}$ \\
& & & \\
\hline
\end{tabular}

GS = Gleason score; ISUP = International Society for Urological Pathology; PSA = prostate-specific antigen. 


\section{Development of AS as a strategy for managing clinically localised PCa}

\section{a. How did the concept of active surveillance arise?}

Early studies found that in some patients, simply observing PCa and not radically treating it in some men, did not lead to a higher risk of death from prostate cancer. Bill-Axelson et al conducted the Scandinavian PCa Group-4 study (SPCG-4) between 1989 and 1999, in which 695 men with localised PCa were either assigned to watchful waiting or radical prostatectomy. ${ }^{8}$ The endpoints were death from $\mathrm{PCa}$, and any death-cause and metastatic disease progression. Eligibility criteria for the study included being less than 75 years of age with a life expectancy of over 10 years. The SPCG-4 results showed that treatment conferred a relative risk of death of 0.56 compared to watchful waiting, whilst the risk of metastases was lower following prostatectomy. For men aged 65 and older at diagnosis, there was no significant reduction in mortality between groups, although there was a slightly lower risk of metastatic progression in those who received surgery. This study therefore demonstrated that essentially doing nothing in some patients, who probably had lower risk disease, would not necessarily cause harm.

In another study, initiated in 1994, the follow-up of PCa Intervention Versus Observation trial (PIVOT), 731 men with clinically localised PCa were randomly assigned to either radical prostatectomy or observation. ${ }^{9}$ This study demonstrated surgery was associated with lower all-cause mortality compared to observation in intermediate-risk disease, but not in low-risk disease over 20 years of followup among men with localized PCa. Disease and treatment-related lifestyle limitations were greater with surgery, especially in the domains of urinary incontinence, and erectile and sexual dysfunction. Surgery was associated with a lower risk of disease progression including biochemical and localised recurrence.

Later, in the mid-2000's, The Prostate Testing for Cancer and Treatment study (ProtecT) randomised men with PCa to either treatment or a protocol to allow treatment with curative intent. ${ }^{10}$ In this study, 1643 patients with PSA detected PCa were assigned to either "active monitoring" (a historical, looser form of AS with less stringent criteria for monitoring), or active treatment, which was either radical prostatectomy or radiotherapy. The ProtecT study included men with low and intermediate risk PCa. The active monitoring protocol was as effective as active treatment at 10 years in terms of overall survival; however, this was at a cost of a two-fold increased risk of the metastatic progression. 
Hence, although there is high quality evidence from randomised controlled trials (RCTs) demonstrating that many patients with localised PCa managed by non-curative interventions or strategies of deferred radical treatments have similar survival outcomes compared with radical treatments, there are significant uncertainties and challenges in interpreting such evidence and extrapolating it to contemporary practice. It is important to note that although those RCTs showed that the majority of patients with localised disease would not be disadvantaged from pursuing non-radical management strategies from a survival perspective, they still had worse cancer outcomes such as cancer progression and development of spread (or metastases). Secondly, those earlier RCTs may already be obsolete, because current protocols of AS differ markedly from those earlier RCTs, in the following ways: (1) More widespread use of PSA testing currently, resulting in a stage migration towards the earlier stages of the disease, ${ }^{11}$ hence current cohorts of patients diagnosed with localised PCa are likely to have an even more favourable prognosis compared with historical cohorts from earlier RCTs; (2) Use of new imaging technologies such as multi-parametric MRI (or mpMRI) scan to improve risk stratification by identifying abnormalities within the prostate gland for more accurate targeted biopsies (such as MRI-fusion prostate biopsies) ${ }^{12}$; (3) More stringent selection criteria, including patients with low-risk disease only; and (4) Use of more rigorous surveillance protocols involving more frequent diagnostic interventions during the surveillance period, including PSA testing, repeat MRI scans, and repeat prostate biopsies at regular intervals.

In addition, it is important to understand the key differences between watchful waiting and AS. AS is targeted at patients with localised PCa who are otherwise eligible for active curative treatments, but in whom a decision is taken to defer such treatments until a point in the future when it is deemed necessary, either based on clinical indications or by patient choice; in contrast, watchful waiting is indicated for patients with localised PCa in whom radical treatments are contraindicated (e.g. due to comorbidities) or who have limited life expectancy such that they are unlikely to benefit from such treatments, given the slow progressive nature of localised PCa. They are monitored instead for the development of locally advanced or metastatic disease, in which case they are treated with palliative treatments including hormonal therapy. Some patients start off being managed in an AS programme, but after a long period of time, as they age or develop unrelated serious conditions such as stroke or heart attack, they are reclassified and leave AS to enter a watchful waiting programme from that point onwards. 
b. What is the evidence of clinical effectiveness of AS from contemporary AS protocols?

In more recent series using more rigorous AS protocols, the rates of metastatic progression are much lower, likely due to modern AS protocols involving stricter patient selection criteria and closer monitoring (see Table 2). Several systematic reviews have summarised the evidence base concerning AS but these reviews were mostly narrative reviews hampered by the absence of prospective comparative studies. ${ }^{13}$ In addition, interpretation of the evidence base was also significantly hindered by heterogeneity of all domains of AS. Follow-up of AS cohorts shows that the relative risk for non-PCa death is 10 times that for PCa mortality. ${ }^{14}$ The follow-up duration of AS cohorts is the main limitation, since in most recent studies of contemporary AS protocols follow-up ranges from less than 1 year to around 8.5 years. 
Table 2. Summary of outcomes from selected contemporary Active Surveillance cohorts

\begin{tabular}{|c|c|c|c|c|c|}
\hline Study & Inclusion criteria & Monitoring plan & $\begin{array}{l}\text { Criteria for initiation of } \\
\text { radical treatment (i.e. } \\
\text { Reclassification) }\end{array}$ & $\begin{array}{l}\text { Median } \\
\text { follow-up } \\
\text { (months) }\end{array}$ & Results \\
\hline $\begin{array}{l}\text { Roemeling } \\
\text { et al. } \\
2007^{15}\end{array}$ & $\begin{array}{l}\text { 1. Clinical stage T1c or T2 } \\
\text { 2. PSA }</-15 \mathrm{n} / \mathrm{ml} \\
\text { 3. Gleason score }<8 \text { on biopsy }\end{array}$ & $\begin{array}{l}\text { Varied due to local practices } \\
\text { Medical history, DRE, } \\
\text { dissemination studies and PSA } \\
\text { semi-annually for } 5 \text { years and } \\
\text { then annually after. }\end{array}$ & Not declared & 41 & $\begin{array}{l}\mathrm{n}=278 \\
29 \% \text { had } \\
\text { treatment } \\
\text { delayed } \\
89 \% \text { survived } \\
\text { overall with } \\
100 \% \text { cause- } \\
\text { specific survival } \\
\text { at } 5 \text { years }\end{array}$ \\
\hline $\begin{array}{l}\text { Khatami } \\
\text { et al. } \\
2007^{16}\end{array}$ & $\begin{array}{l}\text { 1. } 1 \text { or } 2 \text { adjacent cores } \\
\text { 2. Total core cancer length }<2 \mathrm{~mm} \\
\text { 3. Repeat biopsies did not reveal more } \\
\text { cancer }\end{array}$ & $\begin{array}{l}\text { 1. Semi-annual PSA and } \\
\text { clinical investigations } \\
\text { (annually after } 2 \text { years no } \\
\text { progression) } \\
\text { 2. Repeat biopsies in T stage } \\
\text { and or PSA progression }\end{array}$ & $\begin{array}{l}\text { Established PSA, stage or } \\
\text { grade progression. Or patient } \\
\text { desire. }\end{array}$ & 63 & $\begin{array}{l}\mathrm{n}=270 \\
39 \% \text { received } \\
\text { active treatment }\end{array}$ \\
\hline $\begin{array}{l}\text { Carter } \\
\text { et al. } \\
2007^{17}\end{array}$ & 1. Stage $\mathrm{T} 1 \mathrm{c}$ or $\mathrm{Ta}$ & $\begin{array}{l}\text { 1. Semi-annual total PSA and } \\
\text { DRE } \\
\text { 2. Annual prostate biopsy }\end{array}$ & $\begin{array}{l}\text { 1. Gleason } 4 \text { or } 5 \\
\text { 2. }>2 \text { biopsy ores with cancer } \\
\text { or }>50 \% \text { involvement of any } \\
\text { core }\end{array}$ & 41 & $\begin{array}{l}\mathrm{n}=407 \\
59 \% \text { on AS } \\
25 \% \text { deferred } \\
\text { radical treatment } \\
16 \% \text { lost to fu, } \\
\text { withdrew } \\
2 \% \text { died of other } \\
\text { causes }\end{array}$ \\
\hline $\begin{array}{l}\text { Van As } \\
\text { et al. } \\
2008^{18}\end{array}$ & $\begin{array}{l}\text { Patients with adenocarcinoma of the } \\
\text { prostate meeting the following criteria: } \\
\text { 1. Staging T1-T2a, N0-Nx, M0-Mx } \\
\text { 2. PSA }<15 \mathrm{ng} / \mathrm{ml}\end{array}$ & $\begin{array}{l}\text { 1. Serial PSA measurement } \\
\text { 2. Repeat prostate biopsies }\end{array}$ & $\begin{array}{l}\text { 1. PSA velocity }>1 \mathrm{ng} / \mathrm{ml} / \mathrm{yr} \\
\text { 2. Primary Gleason grade }>/= \\
4 \\
\text { Or }\end{array}$ & 22 & $\begin{array}{l}n=326 \\
73 \% \text { remain on } \\
\text { AS }\end{array}$ \\
\hline
\end{tabular}




\begin{tabular}{|c|c|c|c|c|c|}
\hline & $\begin{array}{l}\text { 3. Gleason score }</=7 \text {, primary } \\
\text { Gleason grade }</=3 \\
\text { 4. }</=50 \% \text { positive biopsy cores }\end{array}$ & & 3. $>50 \%$ positive biopsy core & & $\begin{array}{l}20 \% \text { deferred } \\
\text { radical treatment } \\
5 \% \text { changed to } \\
\text { watchful waiting } \\
\text { due to increasing } \\
\text { comorbidity } \\
2 \% \text { died of other } \\
\text { causes } \\
\text { OS } 98 \% \\
\text { CSS } 100 \%\end{array}$ \\
\hline $\begin{array}{l}\text { Soloway } \\
\text { et al. } \\
2010^{19}\end{array}$ & $\begin{array}{l}\text { 1. Gleason }</-6 \\
\text { 2. } \mathrm{PSA}</=10 \\
\text { 3. }</=2 \text { biopsy cores with }</=20 \% \\
\text { tumour in each core }\end{array}$ & $\begin{array}{l}\text { 1. 3-4 monthly PSA and rectal } \\
\text { exam for first } 2 \text { years and } \\
\text { then } 6 \text { monthly } \\
\text { 2. After } 2000 \text { repeat TRUS } \\
\text { biopsy } 9-12 \text { month after first } \\
\text { and then yearly or if dramatic } \\
\text { rise in PSA or change on } \\
\text { DRE. }\end{array}$ & $\begin{array}{l}\text { 1. Gleason grade }>3 \text { on re- } \\
\text { biopsy } \\
\text { 2. Increase tumour volume } \\
\text { measured by percentage of } \\
\text { tumour in each core } \\
\text { 3. Increase in number of } \\
\text { positive cores } \\
\text { 4. Personal preference }\end{array}$ & 45 & $\begin{array}{l}n=99 \\
14 \% \text { received } \\
\text { active treatment } \\
100 \% \text { cause- } \\
\text { specific survival }\end{array}$ \\
\hline $\begin{array}{l}\text { Adamy } \\
\text { et al. } \\
2011^{20}\end{array}$ & $\begin{array}{l}\text { 1. PSA }<10 \mathrm{ng} / \mathrm{ml} \\
\text { 2. No Gleason } 4 \text { or } 5 \text { prostate biopsy } \\
\text { 3. Stage T1-T2a } \\
\text { 4. } 3 \text { or fewer positive biopsy cores out } \\
\text { of } 10 \\
\text { 5. No biopsy containing }>50 \% \text { cancer } \\
\text { involvement }\end{array}$ & $\begin{array}{l}\text { 1. Semi-annual DRE, free and } \\
\text { total PSA } \\
2 \text {. Review of urinary symptoms } \\
\text { and health } \\
\text { 3. Biopsy } 2-3 \text { yearly }\end{array}$ & $\begin{array}{l}\text { When patients no longer met } \\
\text { inclusion criteria. }\end{array}$ & 48 & $n=533-1,000$ \\
\hline $\begin{array}{l}\text { Klotz et al. } \\
2015^{21}\end{array}$ & $\begin{array}{l}\text { 1995-1999: } \\
\text { Gleason score }</=6 \text { and } \mathrm{PSA}</ 10 \\
\text { ng/ml } \\
\text { or } \\
>70 \text { years with } \mathrm{PSA}</=15 \mathrm{ng} / \mathrm{ml} \text { or } \\
\text { Gleason }</=3+4(7) \\
\text { From } 2000 \text { : } \\
\text { Gleason score }</=6 \text { and } \mathrm{PSA}<10 \mathrm{ng} / \mathrm{ml} \\
\text { or patients with favourable }\end{array}$ & $\begin{array}{l}\text { 1. } 3 \text { monthly PSA for } 2 \text { years } \\
\text { then } 6 \text { monthly if stable } \\
\text { 2. Repeat biopsy at } 1 \text { year and } \\
\text { then every } 2-4 \text { years until the } \\
\text { age of } 80\end{array}$ & $\begin{array}{l}\text { 1. PSA Kinetics including PSA } \\
\text { doubling time <3 years from } \\
1996 \text { until } 2008 \text {, then only } \\
\text { indication for repeat } \\
\text { biopsies or multi parametric } \\
\text { MRI } \\
\text { 2. Development of an } \\
\text { unequivocal palpable } \\
\text { nodule on DRE with }\end{array}$ & 77 & $\begin{array}{l}\mathrm{n}=993 \\
27 \% \text { received } \\
\text { active treatment } \\
1.5 \% \text { cause- } \\
\text { specific death } \\
2.8 \% \text { developed } \\
\text { metastatic } \\
\text { disease }\end{array}$ \\
\hline
\end{tabular}




\begin{tabular}{|c|c|c|c|c|c|}
\hline & $\begin{array}{l}\text { intermediate-risk disease (PSA } 10-20 \\
\mathrm{ng} / \mathrm{ml} \text { and/or Gleason score } 3+4 \text { ) with } \\
\text { significant comorbidities and life } \\
\text { expectancy }<10 \text { years }\end{array}$ & & $\begin{array}{l}\text { confirmed histological } \\
\text { progression }\end{array}$ & & \\
\hline $\begin{array}{l}\text { Tosoian et } \\
\text { al. } 2015^{22}\end{array}$ & $\begin{array}{l}\text { 1. Stage T1c } \\
\text { 2. PSA density }<0.15 \mathrm{ng} / \mathrm{mL} \\
\text { 3. Gleason score }</=6 \text { on biopsy } \\
\text { 4. Maximum of } 50 \% \text { cancer } \\
\text { involvement of any biopsy } \\
\text { Also older men with }</=\mathrm{T} 2 \mathrm{a} \text {, PSA } \\
<10 \mathrm{ng} / \mathrm{mL} \text { and Gleason }</=6 \text {. }\end{array}$ & $\begin{array}{l}\text { 1. Semi-annual PSA } \\
\text { measurement } \\
\text { 2. Semi-annual DRE } \\
\text { 3. Annual } 12 \text { to } 14 \text { core } \\
\text { biopsy for most men }\end{array}$ & $\begin{array}{l}\text { Biopsy findings no longer } \\
\text { meeting the inclusion criteria }\end{array}$ & 48 & $\begin{array}{l}99.9 \% \text { CS } \\
\text { mortality at } 15 \\
\text { years } \\
\\
99.4 \% \\
\begin{array}{l}\text { Metastasis-free } \\
\text { survival at } 15 \\
\text { years }\end{array} \\
0.7 \% \text { cause- } \\
\text { specific mortality } \\
4 \% \text { total mortality }\end{array}$ \\
\hline
\end{tabular}




\section{AS in clinical practice}

This section describes and summarises the different domains of active surveillance for clinically localised prostate cancer, namely: (1) Inclusion, recruitment and eligibility; (2) Monitoring and follow-up schedules; (3) Reclassification criteria; and (4) Outcomes which should be prioritised and measured in AS protocols.

\section{a. Inclusion, recruitment and eligibility criteria}

Selection of patients for entry into AS programmes is a critically important domain, because the entire premise of AS is based on the identification of patients at low risk of disease progression, in order to derive the benefits of any deferred active treatment strategy. Consequently, careful risk stratification based on clinical evaluation (e.g. digital rectal examination [DRE] of the prostate which provides local clinical T stage information), PSA level and biopsy Gleason score (or ISUP grade group) is essential. There are many AS guidelines and institutional inclusion criteria. The majority of protocols would only include patients with low-risk disease (Table 1), although there are exceptions; for instance, some protocols and guidelines (e.g. AUA, DUA, Royal Marsden) would include patients with PSA 10-20 $\mathrm{ng} / \mathrm{ml}^{23} 2425$ Some guidelines require a PSA density of $<0.15$ units. The PSA density (PSAd), is a calculation performed at diagnosis and is the serum PSA level $(\mathrm{ng} / \mathrm{mL})$ divided by the volume of the prostate gland $(\mathrm{mL})$. The issue of cancer extent based on biopsy characteristics on histological examination is also becoming increasingly important, although how the extent should be defined (e.g. core involvement, defined as either the $\%$ of volume of cancer within all biopsy cores, or maximum length of involvement of cancer in all cores expressed in $\mathrm{mm}$; or positive cores defined as either \% of cores with cancer out of all biopsy cores, or total number of number of cores with cancer) remains unclear. The thresholds for core involvement and positive cores beyond which patients should be excluded from AS programmes also remain controversial. Most AS guidelines require a maximum extent of cancer per biopsy core $<50 \%$, while the maximum number of positive cores required varies between $<2$ and $<3$. Guidelines including those by I+CS, GSU and FCCG 262728 include a minimum number of cores sampled at the time of biopsy as an inclusion criteria, set between $10-12$, while the AUA guidelines include a minimum number of 10 cores per sample in high risk patients considered for 
AS. ${ }^{29}$ This is a safety mechanism effort to avoid higher volume disease being subjected to AS. The use of mpMRI incorporating T2-weighted sequences, dynamic contrast enhancement (DCE) and dynamicweighted imaging (DWI) as a means of staging, identification of high grade disease (based on the PIRADS-V2 scoring algorithm ${ }^{30}$ which identifies clinically significant disease defined as $\geq$ Gleason grade $3+4=7$ [ISUP grade group 2]), or to facilitate targeted biopsies of areas within the prostate harbouring high grade disease, is on the increase although evidence regarding its effectiveness remains unclear. The vast majority of contemporary AS protocols mandate accurate sampling of prostate biopsies to ensure clinically significant disease is not missed, and this is achieved through mpMRI targeted biopsies (called fusion biopsies) usually combined with systematic biopsies to ensure comprehensive sampling of prostate tissues, or transperineal template mapping biopsies, or saturation transrectal ultrasoundguided prostate biopsies.

\section{b. Monitoring and follow-up schedules}

Monitoring and follow-up schedules aim to detect disease progression early and achieve timely treatment if necessary. These include three main components, which are measured at regular intervals: (1) Serial serum PSA levels; (2) DRE; and (3) repeat TRUS-guided prostate biopsy sampling. Other proposed parameters include PSA kinetics, derived from serial PSA measurements (e.g. PSA velocity or doubling time), and use of mp-MRI. The timing and frequency of these investigations constitute the variation between institution-specific protocols. Serum PSA measurements are mostly performed at intervals of 3-6 months, often depending on concerns over disease progression or duration of AS. DRE is recommended by the majority of guidelines every 6-12 months. Repeat biopsy scheduling, which is used as a tool to evaluate formal disease reclassification, is recommended at more diverse intervals. Most guidelines recommend a second biopsy within 6-18 months after diagnosis, followed by repeat biopsies every 3-5 years, although there is significant heterogeneity across protocols and guidelines. A retrospective study by the Movember foundation included data of 15,101 patients from 25 established AS cohorts worldwide. The study found inclusion criteria were generally followed well, but adherence to repeat biopsies reduces with time.$^{31}$ Similar findings have been shown in research by other groups. 32 The use of mp-MRI has been explored as an adjunct to the above methods, to decrease the frequency and burden of frequent repeat biopsies. Studies have described mp-MRI, followed by MRI-guided 
biopsy for suspicious prostatic lesions, to increase detection rates of intermediate or high-risk PCa, as well as reduce in the number of confirmatory TRUS-guided biopsies.

\section{c. Reclassification criteria}

Reclassification is defined as an event whereby patients on AS leave the programme either to pursue active curative treatment, or watchful waiting. The reasons for reclassification include clinical indications (especially disease progression, increase in cancer grade or increase in disease extent), patient choice (for instance, due to patient anxiety or psychological distress), or change in circumstances (e.g. development of serious unrelated disease such as stroke or heart attack which impairs fitness for subsequent active curative interventions, or old age after being on active surveillance for a long period, hence rendering continued active surveillance inappropriate). As in the other domains, there is significant variability and heterogeneity amongst different AS protocols regarding reclassification criteria, hence making comparisons of clinical effectiveness across protocols difficult to interpret.

\section{d. Core outcomes for measurement in AS protocols}

It is important to measure and report the most important outcomes in a standardised manner, to enable meaningful audit of clinical effectiveness and harms, and comparative assessment across different protocols. Different outcomes have been reported, including: (1) Oncological outcomes (i.e. overall and cancer-specific survival, clinical progression defined as development of locally advanced metastatic disease); (2) Reclassification (defined as leaving AS for reasons stated a priori); (3) Functional outcomes (including urinary and sexual function); (4) Quality of life outcomes (including generic and health-related QoL outcomes); and (5) Measures of anxiety, depression and mental health and well-being. A core outcome set for localised prostate cancer interventions including AS has been reported previously, ${ }^{33}$ and a core outcome set specific for AS was developed by consensus recently. ${ }^{34}$ 


\section{Patient perspectives}

\section{a. Patient compliance and adherence}

Adherence to AS programmes is important to consider and measure, because AS is associated with some adverse outcomes, including a transient reduction in quality of life, anxiety, and economic and psychological burden imposed by regular and repeated clinic visits for PSA blood tests, DRE, mpMRI and repeat biopsies. Repeat prostate biopsies are also associated with a risk of complications including haematospermia, haematuria, pelvic pain, rectal bleeding and urosepsis. Understandably, adherence to PSA measurements is higher compared to adherence to repeat prostate biopsies. In real world studies, looking at the differences between research and clinical practice, less than $70 \%$ of patients undergo the first repeat biopsy. ${ }^{29}$ This highlights a substantial gap regarding AS protocol adherence between the research setting and clinical practice. An Australian study assessing adherence to the recommended AS protocol of at least 3 PSA measurements and at least one biopsy in the 2 years postdiagnosis, found only $26.5 \%$ adherence. Interestingly, men diagnosed in public hospitals were less likely to adhere to the follow-up schedule compared to men diagnosed in private hospitals, implying health-related inequalities influence adherence to follow-up. ${ }^{35} \mathrm{~A}$ systematic review assessing factors that affect men's choice of and adherence to AS has highlighted the key themes of: 1) Patient and tumour factors; 2) Family and social support; 3) Healthcare provider; 4) Healthcare organisation; and 5) Health policy. They suggest that managing AS in a similar way to other chronic diseases, with standardised clinician and patient education, decision aids and treatment plans, and nationally agreed guidelines, may increase patient adherence..$^{36}$

\section{b. Non-oncological benefits of AS for patients and society}

Surveillance-related anxiety, associated with an awareness of an untreated cancer diagnosis, coupled with the regular tests and examinations that are required might be expected from some

patients. However, an individual's close clinical contact with follow-up by healthcare professionals serves as reassurance that their condition is being acknowledged and actively monitored and being under the constant supervising care of specialist clinicians. Several studies have in fact shown the 
minimal impact of AS on mental health. ${ }^{37}$ The premorbid mental state of a patient is a relevant consideration prior to the commencement of AS and in selected patients additional support may be required. Van den Bergh et al have conducted several studies on anxiety in AS. Patients surveyed on AS for early PCa reported less anxiety and depression than those for active treatments and control values. ${ }^{38}$ Higher PSA levels were associated with increased anxiety levels, and pre-morbid neurotic personality was also predictive of self-reported anxiety. Patient-reported anxiety was lower at 9 months from diagnosis, compared to initial anxiety scores recorded at the time of diagnosis.

Finally, AS offers an economic advantage over immediate unnecessary treatment through its lower comparative cost. A USA-based simulation of 120,000 men enrolling in AS over radical treatment projected cost savings of nearly $\$ 2$ billion USD over 5 years, whilst a Canadian study estimated a saving of $\$ 96.1$ million CAD for each annual cohort of incident PCa to the Canadian health system. ${ }^{39,40}$

\section{Pitfalls and challenges in undertaking AS due to clinical heterogeneity and future directions}

As outlined in section 3, there is considerable variability and clinical heterogeneity across AS protocols, regarding the following domains: (1) Patient selection, inclusion and eligibility criteria, definitions and thresholds (including role of mpMRI, how disease extent based on biopsy characteristics should influence decisions regarding inclusion or exclusion, and whether patients with intermediate-risk disease should be eligible for AS); (2) Monitoring and follow-up schedules (including frequency and type of imaging such as mpMRI scan, type and frequency of repeat prostate biopsies and whether they should be triggered or untriggered, the role of MRI-targeted biopsies or transperineal template biopsies, use of PSA kinetics and density, and frequency of clinical follow-up); and (3) Reclassification criteria (especially in terms of when active treatment should be instigated). There is a need to standardise at the very least definitions of terms, thresholds and conduct of AS across all domains to enable more meaningful assessments of clinical effectiveness amongst protocols and against standard radical treatments, and clinical audit for individual protocols. Several attempts have been made to address clinical heterogeneity and standardise all elements of AS using consensus methodology, ${ }^{41}$ the latest of which is the DETECTIVE Study. ${ }^{34}$ 
In spite of these efforts, significant uncertainties remain. The most important of these can be summarised as follows: (1) The role of mpMRI in inclusion and recruitment, monitoring and in reclassification; (2) Thresholds regarding the extent of disease on biopsy in influencing inclusion, exclusion and reclassification; and (3) The role of triggered and untriggered (i.e. per protocol) diagnostic interventions during monitoring, including repeat biopsies and how they should be performed and when, and if triggered what the triggers of repeat biopsies should be. It is hoped that comparative data from contemporary studies will provide some clarity to the above questions as the data mature.

Accurate estimation of life expectancy for individual patients is required to select suitable patients for AS. Current tools are based on generic measures of frailty, health status and comorbidities, ${ }^{3}$ but there is a need to use more accurate tools which individualise the estimation based on the interaction between essential variables including age, ethnicity, social class, family history, smoking status and specific co-morbidities and their severity and impact on functioning. The role of MRI in detecting the grade of disease, biomarkers, (serum or urine), and genetic profiles are evolving areas and might contribute, in the future, to predicting the probability of disease aggression and therefore patient suitability for AS. Large prospective studies are needed to clarify the use of serum biomarkers, genetic panels, actuarial age prediction tools, and higher resolution MRI. At present, consensus guidance released by international guideline panels should be used, and different AS protocols should be compared in prospective cohort, or even randomised studies if appropriate.

The role of mpMRI deserves special mention. Recent high quality clinical trials on the role of $\mathrm{mpMRI}$ as a triage diagnostic test prior to prostate biopsies have redefined the role of $\mathrm{mpMRI}$ in the diagnostic pathway, as it has been shown to enhance the detection of clinically significant prostate cancer whilst reducing the identification of clinically insignificant disease and reducing the need for unnecessary biopsies. ${ }^{4243}$ Whilst those studies were not designed to deal specifically with AS, the relevance of the findings to contemporary practice of AS is that the impact on patient selection for inclusion/exclusion during recruitment and as a trigger for repeat biopsies during monitoring may potentially be revolutionary. Nevertheless, due to the lack of robust comparative data specifically for AS, most guideline authorities remain cautious over recommending mpMRI as an essential component for AS, and regard it as optional instead. 


\section{Summary of guideline recommendations for healthcare professionals regarding AS}

Although there is some variation in recommendations from guideline authorities regarding the practice of AS, there is significant consistency and common ground amongst them. The European Association of Urology PCa Guideline Panel has updated its clinical practice recommendations for AS for 2020 following a review of the evidence base and from findings of the DETECTIVE consensus study; ${ }^{34}$ these are summarised in Table 3.

Table 3: European Association of Urology Prostate Cancer Guidelines (2020):

Recommendations for Active Surveillance ${ }^{3}$ 


\section{Implications for Nursing Practice}

The practice of AS involves a multi-disciplinary team consisting of a myriad of different healthcare professionals including oncology nurses, urologists, oncologists, pathologists and radiologists. Nurses play an essential role in managing and delivering AS programmes, being directly involved with all stages of AS, from patient assessment, selection and recruitment, to counselling and facilitating decision-making during enrolment and reclassification, and from organising and administering diagnostic interventions including prostate biopsies during monitoring, to ensuring patients' needs are being met throughout the duration of AS. It was historically recognised in 2006 that nurses were ideally placed to develop advanced roles in cancer care to help meet the increased demand on clinical services. ${ }^{44}$ Several reports have identified benefits of nurse-led AS services as an alternative to standard consultant-led clinics. ${ }^{45}$ Benefits may include, efficient use of resources, coordination and continuity of care, freeing up consultants which may increase surgical capacity (ref). Noteworthy, nurses providing this advanced level of clinical care and autonomy must be safely embedded within the multidisciplinary team. Evidence has underscored that men undergoing AS for PCa can experience anxiety, depression, uncertainty, and fear of cancer progression. ${ }^{46}$ Given the potential psychological sequalae in men affected by prostate cancer implementing holistic needs assessments (HNA) in routine clinical care ensures timely supportive care intervention. ${ }^{47}$ Supportive 
care is defined as requirements for care to enable adaption and coping, optimise understanding and informed decision-making, and minimise decrements in physical, practical, emotional, spiritual and social functioning. ${ }^{48}$ HNAs are completed by patients to evaluate their own perceptions of needs in relation to quality of life. HNAs reveal patients' and partners/caregivers' highest concerns and unmet needs, enabling healthcare professionals to personalize and develop shared self-management care plans. Without the integration of HNAs symptoms, psychological burden and other impacts on quality of life may go under-recognised and under-treated for men affected by prostate cancer. In summary, nurses have a crucial role in maintaining AS programmes and in ensuring their enduring success.

\section{Conclusions}

This article provides an overview of active surveillance for the management of clinically localised prostate. AS has emerged as a feasible alternative to radical treatment options especially for low-risk disease, primarily as a means of avoiding unnecessary treatments at the early stages of the disease and hence avoiding over-treatment, whilst at the same time providing a means of monitoring individuals through regular clinical assessments, PSA testing, imaging using MRI scans and regular repeat prostate biopsies, so that those who show evidence of disease progression, disease upgrading or increase in disease extent can be identified and treated curatively. In practice, the conduct of AS involves 3 domains: Inclusion and recruitment, Monitoring and follow-up, and Reclassification. Criteria and thresholds exist for different elements within each domain and these have been summarised in this article. There is evidence of effectiveness from several long-term studies involving earlier and less stringent versions of AS such as observation or active monitoring which have shown it to be safe and comparable to radical treatments such as surgery and radiotherapy in terms of overall survival for men with localised disease. The version of AS as we know today has evolved from those earlier versions, involving a greater use of technology (such as MRI scan) and improved means of detecting clinically significant disease through the use of better biopsy techniques (such as MRI-targeted biopsies) and more stringent selection and monitoring of patients. As such, the long-term outcomes of AS are likely to be more favourable than those observed previously. However, some issues and uncertainties persist in regard to the conduct of AS, including heterogeneity of definitions, criteria and thresholds for each of the domains, and regarding the most optimum diagnostic interventions during recruitment and 
monitoring; these continue to pose a challenge to healthcare professionals. Efforts have been made to standardise the practice and conduct of AS based on consensus methods, and these are continuing. As data from high-quality prospective comparative studies and randomised trials mature, the practice of AS will continue to evolve and be refined, and long-term outcomes are expected to continue to improve. This article summarises current clinical practice guideline recommendations from guideline authorities, which should help healthcare practitioners in managing patients on AS programmes. Finally, the crucial role oncology nurses play in AS programmes must be acknowledged and emphasised.

\section{References}

1. Key Statistics for Prostate Cancer | Prostate Cancer Facts. Accessed May 20, 2020. https://www.cancer.org/cancer/prostate-cancer/about/key-statistics.html

2. Prostate cancer statistics | Cancer Research UK. Accessed May 20, 2020.

https://www.cancerresearchuk.org/health-professional/cancer-statistics/statistics-by-cancertype/prostate-cancer

3. EAU Guidelines: Prostate Cancer | Uroweb. Accessed May 20, 2020. https://uroweb.org/guideline/prostate-cancer/

4. Epstein JI, Egevad L, Amin MB, Delahunt B, Srigley JR, Humphrey PA. The 2014 international society of urological pathology (ISUP) consensus conference on gleason grading of prostatic carcinoma definition of grading patterns and proposal for a new grading system. Am J Surg Pathol. 2016;40(2):244-252. doi:10.1097/PAS.0000000000000530

5. D’Amico A V., Whittington R, Bruce Malkowicz S, et al. Biochemical outcome after radical prostatectomy, external beam radiation therapy, or interstitial radiation therapy for clinically localized prostate cancer. J Am Med Assoc. 1998;280(11):969-974. doi:10.1001/jama.280.11.969

6. Moon K, Stukenborg GJ, Keim J, Theodorescu D. Cancer incidence after localized therapy for prostate cancer. Cancer. 2006;107(5):991-998. doi:10.1002/cncr.22083

7. Donovan JL, Hamdy FC, Lane JA, et al. Patient-reported outcomes after monitoring, surgery, 
or radiotherapy for prostate cancer. N Engl J Med. 2016;375(15):1425-1437.

doi:10.1056/NEJMoa1606221

8. Bill-Axelson A, Holmberg L, Garmo H, et al. Radical prostatectomy or watchful waiting in prostate cancer — 29-year follow-up. N Engl J Med. 2018;379(24):2319-2329. doi:10.1056/NEJMoa1807801

9. Wilt TJ, Jones KM, Barry MJ, et al. Follow-up of prostatectomy versus observation for early prostate cancer. N Engl J Med. 2017;377(2):132-142. doi:10.1056/NEJMoa1615869

10. Hamdy FC, Donovan JL, Lane JA, et al. 10-Year Outcomes After Monitoring, Surgery, or Radiotherapy for Localized Prostate Cancer. N Engl J Med. 2016;375(15):1415-1424. doi:10.1056/NEJMoa1606220

11. Schröder FH, Hugosson J, Roobol MJ, et al. Screening and Prostate-Cancer Mortality in a Randomized European Study. N Engl J Med. 2009;360(13):1320-1328. doi:10.1056/NEJMoa0810084

12. Bryant RJ, Yang B, Philippou Y, et al. Does the introduction of prostate multiparametric magnetic resonance imaging into the active surveillance protocol for localized prostate cancer improve patient re-classification? BJU Int. 2018;122(5):794-800. doi:10.1111/bju.14248

13. Thomsen FB, Brasso K, Klotz LH, Røder MA, Berg KD, Iversen P. Active surveillance for clinically localized prostate cancer - A systematic review. J Surg Oncol. 2014;109(8):830-835. doi:10.1002/jso.23584

14. Klotz L, Vesprini D, Sethukavalan $P$, et al. Long-term follow-up of a large active surveillance cohort of patients with prostate cancer. J Clin Oncol. 2015;33(3):272-277. doi:10.1200/JCO.2014.55.1192

15. Roemeling S, Roobol MJ, de Vries SH, et al. Active Surveillance for Prostate Cancers Detected in Three Subsequent Rounds of a Screening Trial: Characteristics, PSA Doubling Times, and Outcome. Eur Urol. 2007;51(5):1244-1251. doi:10.1016/j.eururo.2006.11.053

16. Ali K, Gunnar A, Jan-Erik D, Hans L, Pär L, Jonas H. PSA doubling time predicts the outcome after active surveillance in screening-detected prostate cancer: Results from the European 
randomized study of screening for prostate cancer, Sweden section. Int J Cancer. 2007;120(1):170-174. doi:10.1002/ijc.22161

17. Carter HB, Kettermann A, Warlick C, et al. Expectant Management of Prostate Cancer With Curative Intent: An Update of The Johns Hopkins Experience. J Urol. 2007;178(6):2359-2365. doi:10.1016/j.juro.2007.08.039

18. van As NJ, Norman AR, Thomas K, et al. Predicting the Probability of Deferred Radical Treatment for Localised Prostate Cancer Managed by Active Surveillance. Eur Urol. 2008;54(6):1297-1305. doi:10.1016/j.eururo.2008.02.039

19. Soloway MS, Soloway CT, Eldefrawy A, Acosta K, Kava B, Manoharan M. Careful selection and close monitoring of low-risk prostate cancer patients on active surveillance minimizes the need for treatment. Eur Urol. 2010;58(6):831-835. doi:10.1016/j.eururo.2010.08.027

20. Adamy A, Yee DS, Matsushita K, et al. Role of prostate specific antigen and immediate confirmatory biopsy in predicting progression during active surveillance for low risk prostate cancer. J Urol. 2011;185(2):477-482. doi:10.1016/j.juro.2010.09.095

21. Klotz L, Vesprini $D$, Sethukavalan $P$, et al. Long-term follow-up of a large active surveillance cohort of patients with prostate cancer. J Clin Oncol. 2015;33(3):272-277. doi:10.1200/JCO.2014.55.1192

22. Tosoian JJ, Mamawala M, Epstein JI, et al. Intermediate and longer-term outcomes from a prospective active-surveillance program for favorable-risk prostate cancer. J Clin Oncol. 2015;33(30):3379-3385. doi:10.1200/JCO.2015.62.5764

23. Prostate Cancer: Clinically Localized Guideline - American Urological Association. Accessed May 20, 2020. https://www.auanet.org/guidelines/prostate-cancer-clinically-localized-guideline

24. Prostate cancer - General - Guideline - Guidelines database. Accessed May 20, 2020. https://richtlijnendatabase.nl/richtlijn/prostaatcarcinoom/algemeen.html

25. Selvadurai ED, Singhera M, Thomas K, et al. Medium-term outcomes of active surveillance for localised prostate cancer. Eur Urol. 2013;64(6):981-987. doi:10.1016/j.eururo.2013.02.020

26. Guía de Práctica Clínica Para La Detección Temprana, Diagnóstico, Tratamiento, Seguimiento 
y Rehabilitación Del Cáncer de Próstata| GPC-2013-21. Accessed May 20, 2020.

www.colciencias.gov.co

27. AWMF: Detail. Accessed May 20, 2020. https://www.awmf.org/leitlinien/detail/l//043022OL.html

28. Työryhmä. SLD ja SU ry:n asettama. Eturauhassyöpä (online). Helsinki Suom Lääkäris Duodecim (viitattu 13022019) Saatavilla internetissä www.kaypahoito.fi. Published online 2014:1-19.

29. Komisarenko M, Martin LJ, Finelli A. Active surveillance review: Contemporary selection criteria, followup,compliance and outcomes. Transl Androl Urol. 2018;7(2):243-255. doi:10.21037/tau.2018.03.02

30. Weinreb JC, Barentsz JO, Choyke PL, et al. PI-RADS Prostate Imaging - Reporting and Data System: 2015, Version 2. Eur Urol. 2016;69(1):16-40. doi:10.1016/j.eururo.2015.08.052

31. Bruinsma SM, Zhang L, Roobol MJ, et al. The Movember Foundation's GAP3 cohort: a profile of the largest global prostate cancer active surveillance database to date. BJU Int. 2018;121(5):737-744. doi:10.1111/bju.14106

32. Kalapara AA, Verbeek JFM, Nieboer D, et al. Adherence to Active Surveillance Protocols for Low-risk Prostate Cancer: Results of the Movember Foundation's Global Action Plan Prostate Cancer Active Surveillance Initiative. Eur Urol Oncol. 2020;3(1):80-91. doi:10.1016/j.euo.2019.08.014

33. MacLennan S, Williamson PR, Bekema H, et al. A core outcome set for localised prostate cancer effectiveness trials. BJU Int. 2017;120(5):E64-E79. doi:10.1111/bju.13854

34. Lam TBL, MacLennan S, Willemse PPM, et al. EAU-EANM-ESTRO-ESUR-SIOG Prostate Cancer Guideline Panel Consensus Statements for Deferred Treatment with Curative Intent for Localised Prostate Cancer from an International Collaborative Study (DETECTIVE Study). Eur Urol. 2019;76(6):790-813. doi:10.1016/j.eururo.2019.09.020

35. Evans MA, Millar JL, Earnest A, et al. Active surveillance of men with low risk prostate cancer: Evidence from the prostate cancer outcomes registrye - Victoria. Med J Aust. 
2018;208(10):439-443. doi:10.5694/mja17.00559

36. Kinsella N, Stattin P, Cahill D, et al. Factors Influencing Men's Choice of and Adherence to Active Surveillance for Low-risk Prostate Cancer: A Mixed-method Systematic Review [Figure presented]. Eur Urol. 2018;74(3):261-280. doi:10.1016/j.eururo.2018.02.026

37. Bellardita L, Valdagni R, Van Den Bergh R, et al. How does active surveillance for prostate cancer affect quality of life? A systematic review. Eur Urol. 2015;67(4):637-645. doi:10.1016/j.eururo.2014.10.028

38. Venderbos LDF, Van Den Bergh RCN, Roobol MJ, et al. A longitudinal study on the impact of active surveillance for prostate cancer on anxiety and distress levels. Psychooncology. 2015;24(3):348-354. doi:10.1002/pon.3657

39. Dragomir A, Cury FL, Aprikian AG. Active surveillance for low-risk prostate cancer compared with immediate treatment: a Canadian cost comparison. C Open. 2014;2(2):E60-E68. doi:10.9778/cmajo.20130037

40. Keegan KA, Dall'Era MA, Durbin-Johnson B, Evans CP. Active surveillance for prostate cancer compared with immediate treatment: An economic analysis. Cancer. 2012;118(14):3512-3518. doi:10.1002/cncr.26688

41. Bruinsma SM, Roobol MJ, Carroll PR, et al. Expert consensus document: Semantics in active surveillance for men with localized prostate cancer-results of a modified Delphi consensus procedure. Nat Rev Urol. 2017;14(5):312-322. doi:10.1038/nrurol.2017.26

42. Ahmed HU, El-Shater Bosaily A, Brown LC, et al. Diagnostic accuracy of multi-parametric MRI and TRUS biopsy in prostate cancer (PROMIS): a paired validating confirmatory study. Lancet. 2017;389(10071):815-822. doi:10.1016/S0140-6736(16)32401-1

43. Kasivisvanathan V, Rannikko AS, Borghi M, et al. MRI-targeted or standard biopsy for prostate-cancer diagnosis. N Engl J Med. 2018;378(19):1767-1777. doi:10.1056/NEJMoa1801993

44. Department of Health. (No Title). Accessed May 20, 2020. http://www.nursingleadership.org.uk/publications/settingthedirection.pdf 
45. Lewis $\mathrm{R}$, Neal RD, Williams $\mathrm{NH}$, et al. Nurse-led vs. conventional physician-led follow-up for patients with cancer. J Adv Nurs. 2009;65(4):706-723. doi:10.1111/j.1365-2648.2008.04927.x

46. Oliffe LJ, Davison JB, Pickles T, Mróz L. The self-management of uncertainty among men undertaking active surveillance for low-risk prostate cancer. Qual Health Res. 2009;19(4):432443. doi: $10.1177 / 1049732309332692$

47. Nanton V, Appleton R, Dale J, et al. Integrated Care in Prostate Cancer (ICARE-P): Nonrandomized Controlled Feasibility Study of Online Holistic Needs Assessment, Linking the Patient and the Health Care Team. JMIR Res Protoc. 2017;6(7):e147. doi:10.2196/resprot.7667

48. Paterson C, Robertson A, Smith A, Nabi G. Identifying the unmet supportive care needs of men living with and beyond prostate cancer: A systematic review. Eur J Oncol Nurs. 2015;19(4):405-418. doi:10.1016/j.ejon.2014.12.007 